\title{
Motivation for the Design and Implementation of a SMS Slang Converter for Android Devices
}

\author{
http://dx.doi.org/10.3991/ijim.v10i1.4492 \\ C.N. Udanor and C.I. Nwoye \\ University of Nigeria Nsukka, Nigeria
}

\begin{abstract}
The mobile phone no doubt has become everyone's personal companion. Its applicability keeps increasing as every new day introduces new application. It has grown beyond a mere communication device to a learning, entertainment, as well as health diagnostic tool. The mobile phone has found close companionship among students and youths. Young people are always in a hurry to do everything, including writing proper grammar in SMS. Mobile phone Short Message System (SMS) and the social networking media have adversely affected ourstudents'ability to write good and proper English grammar. The older generation is offended and appalled at the effort they have to put in trying to decipher text messages sent by their children and wards, while the younger generation find slangs a very convenient and economic way of communication. This work presents a needs assessment report in which over $90 \%$ of respondents expressed desire to have an application that converts SMS slang, as well as the design and implementation of a short message slang converter from slang to proper English language, as well as the reverse. The application is designed following the OOAD methodology and built for the Android devices with ADT 4.2 SDK (Kit Kat). Results from user evaluation show that using 'human interpretive compression' the app could achieve a compression that reduces message length by over forty percent therefore reducing the cost of the SMS, time and bandwidth, as well as giving the recipient the ability to effortlessly decipher a coded message. Users also are able to build their own slang and equivalent English dictionary.
\end{abstract}

Index Terms-SMS, mobile phone, short word, full word, slang, Android.

\section{INTRODUCTION}

Since the introduction of the Global System for Mobile communication, GSM, the Short Message Service (SMS) has stood out as one of the most frequently and widely used service across all ages. Over 350 billion SMS messages are exchanged across the world's mobile networks every month, out which more than $15 \%$ are classified as commercial or marketing messages [1]. SMS is a text messaging service component of phone, Web, or GSM which uses a standardized communications protocols to allow fixed line or mobile phone devices exchange short messages [2]. The SMS that is used today originated from radio telegraphy in radio memo pagers using standard phone protocols. These protocols were defined in 1985 as part of the GSM series of standards [3] as a means of sending messages of up to 160 characters, according to the work of Friedhelm Hillebrand [4]. Support for SMS has grown beyond mobile to mobile to include other technologies like ANSI CDMA networks and Digital AMPS, as well as satellite and landline networks. Apart from being used as a means of communication between users, SMS application has grown into commercial usage as a means of product and service advertising. It is also widely used in Mobile Banking (or M-Banking) for SMS transaction alerts, mobile money services, etc. In public service announcements, SMS is used to broadcast text messages to a large community of people in the form of bulk SMSs. Health and relationship tips are also broadcast to both subscribed and unsubscribed users through SMS. According to a study [5], about $82 \%$ of young adults say that they text their romantic partners multiple times a day. From the study, some respondents suggested that frequent text message have improved their relationships.

The use of abbreviation in SMS language have become a part of the multilingual world in the recent past. SMS language aims at creating communication by means of simple structures [11]. In SMS language or slang a whole word may be created by using single letters, numbers or pictures. For example: the letter $u$ replaces you. For terms and words that do not have common abbreviations, users usually eliminate the vowels from the statement and the person who reads it, "builds" the word by adding missing vowels (e.g. keyboard becomes kybrd and dictionary becomes dctnry). The reader always has to interpret the extended and short forms of terminology according to the situation and context in which they are used, because there are a lot of examples of phrases or words that use similar abbreviations. For example: lol could mean lots of love or laugh out loud and cryn could mean cryin (g) or crayon. If somebody writes ttyl, lol, he/she means talk to you later lots of love instead of talk to you later laugh out loud. Moreover, omg, lol imply: oh my god, laugh out loud instead of oh my god, lots of love. Onw usually means oh no way! All conceivable types of feature can be juxta-

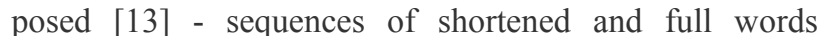
(hldmecls "hold me close"), logograms and shortened words (2bctnd "to be continued"), logograms and nonstandard spellings (cu2nite) and so on. There are no less than four processes combined in iowan 2 bwu "I only want to be with you" - full word + an initialism + a shortened word + two logograms + an initialism + a logogram. And some messages contain unusual processes: in iohis4u "I only have eyes for you", we see the addition of a plural ending to a logogram. One characteristic runs through all these examples: the letters, symbols and words are run together, without spaces. This new style of writing has been termed so many things, "slang", "textese", "slanguage", "texism", etc.

In the remaining part of this paper we shall review related works, analyze the responses of a needs assessment questionnaire and the proposed system, as well as show 
the implementation and the result of the system that converts to and from SMS slang.

\section{RELATED WORKS}

A number of studies have been carried out in universities, polytechnics and high schools to determine the effect of the frequent use of SMS slang among students. While some see the use of SMS slang by students as a threat to the quality of written English language, as such practice of code-switching and code-mixing break grammatical rules [8][10], others think that using SMS in language learning is one of the best opportunities for language learners to extend and increase their learning outside of their classrooms whenever and wherever they desire [6]. Shazia Aziz et al [7] studied the effect of text messaging in English writing among students and teen agers by subjecting fifty students to essay writing. At the end of the study they concluded that SMS texting does not affect students' English, as according to them, there were only punctuation errors, which they said can be as a result of carelessness. But the weakness of this study is that the students were aware they were being tested to know if SMS language will be evident in their writing. Geertsema et. al. [15] seems to think otherwise. In their study on the effect of SMS language on Grade 8 and 9 English (as Home Language) educators in Gauteng, South Africa, the results indicated that the majority of educators viewed SMS language as having a negative influence on the written language skills of Grade 8 and 9 learners. This, according to them is evidenced in their spelling, punctuation and sentence length. Some researchers fear that if urgent steps are not taken at curbing the frequent use of chat room and SMS slang by students in formal writing and examination they may evolve into teachers, who will teach the next generation [8][9].

There is also the fear that SMS may in no distant time produce a new variation of English language known as Textese, chatspeak, and texting language [9]. The use of SMS has changed social interaction patterns, and thus is creating a new socio-cultural scenario [10]. Educators also fear that in addition to the use of SMS slangs, number and letter homophones, contraction and non-conventional spelling, the use of emoticon is another dangerous trend among high school and undergraduate students [10]. Though [16] sees the use of emoticons as a means of expressing feelings and not necessarily weakness in writing. The use of emoticons replace words completely, sometimes they are also used as instruments of abuse. In another study among middle and high school students[12], about two-thirds of the middle and high school teachers surveyed in the study said that "digital tools make students more likely to take shortcuts in their writing and nearly half said these tools make students more likely to "write too fast and be careless." The teachers also observed that there is "an increasingly ambiguous line between 'formal' and 'informal' writing" and the use of informal language and style in formal writing assignments.

Crystal [13] likens the fears educators express about the texting to the fears that were expressed when the printing press, telegraph, telephone and broadcasting were invented. According to him, many 'thought them to be the invention of the devil because they would put false opinions into people's minds'. He dismissed the fact that people have been arguing that new technology of SMS would have disastrous consequences for language. He further states that the slangs used in SMS have been in use in chatrooms before the arrival of the mobile and SMS. He concluded, "but it is merely the latest manifestation of the human ability to be linguistically creative and to adapt language to suit the demands of diverse settings. There is no disaster pending. We will not see a new generation of adults growing up unable to write proper English. The language as a whole will not decline. In texting what we are seeing, in a small way, is language in evolution." Dansieh [14], however does not agree with Crystal [13]. He said that Crystal's generalization of the positive impact of texting could be misleading as his research focused on a population that are conservative with their native language, unlike in other situations where English is taken as a second language and not the native language. He argued that $83 \%$ and $70 \%$ of lecturers and students, respectively surveyed in his work admitted that SMS language can harm their writing skill. But Wood et. al.[16] also re-emphasizing Crystal's claims says that "research has demonstrated that use of texting slang (textisms) when text messaging does not appear to impact negatively on children's literacy outcomes and may even benefit children's spelling attainment. However, less attention has been paid to the impact of text messaging on the development of children's and young people's understanding of grammar". Their findings reinforce the need to differentiate between the deliberate violation of grammatical or orthographic convention and genuine lack of understanding.

\section{ReSEARCh Methods And PROCEDURE}

Questionnaires were designed and self-administered to undergraduate and post-graduate students as well as staff in the Departments of Computer Science, Statistics and ICT of University of Nigeria. The purpose of this questionnaire was for needs assessment. One hundred and three questionnaires were distributed to students and staff, out of which $82 \%$ respondents were undergraduates, $7.7 \%$ were postgraduate students and $9 \%$ were staff. All questionnaires were filled and returned appropriately. A total of 61 males and 42 females responded, respectively..

The responses would determine the justification for developing the app. The responses were analyzed to determine the following:

- The category of users that will most favour the use of the application

- The motivation for the use of SMS slang

- The population that are in need of an SMS slang converter

- If the use of SMS slang affects the formal writing

The responses are shown in the following charts, while the findings are summarized in section 3.1. Software engineering methods were adopted in the analysis and the development of the system. The application was uploaded for users to download and install in their phones free of charge and evaluate its performance by filling user evaluation forms online. 


\section{Category of Respondents} Staff

$10 \% \quad P G$

Students

$8 \%$

UG

Students

$82 \%$

Figure 1. Category of respondents' pie chart

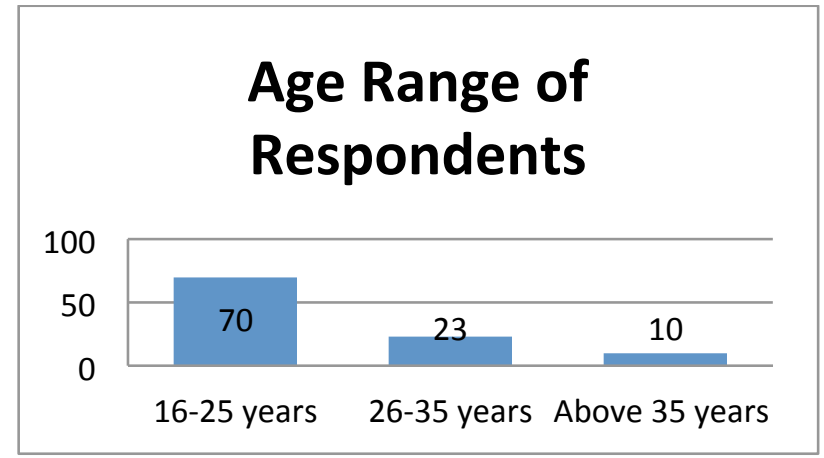

Figure 2. Age range of respondents

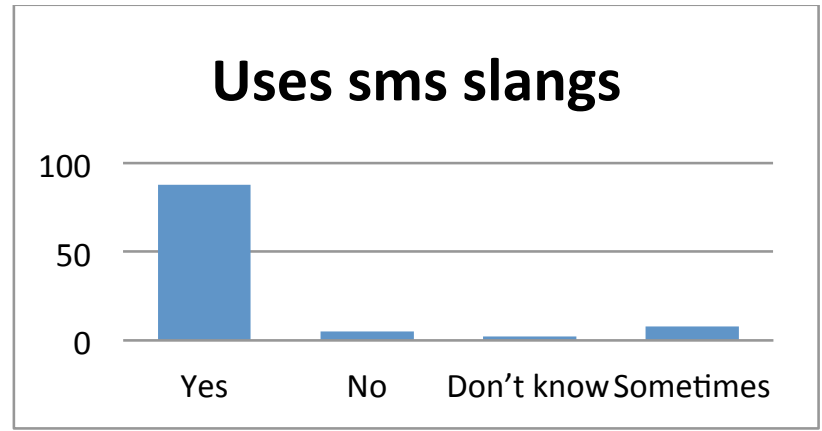

Figure 3. Respondents who use SMS slangs

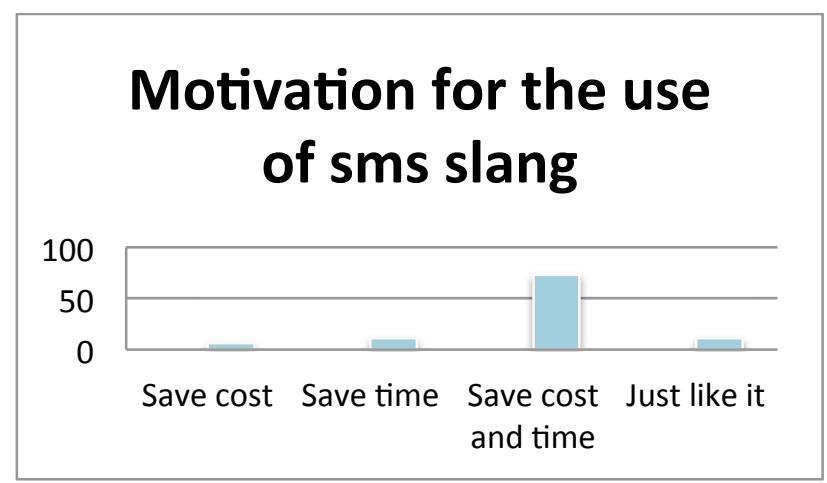

Figure 4. Motivation for using sms slangs

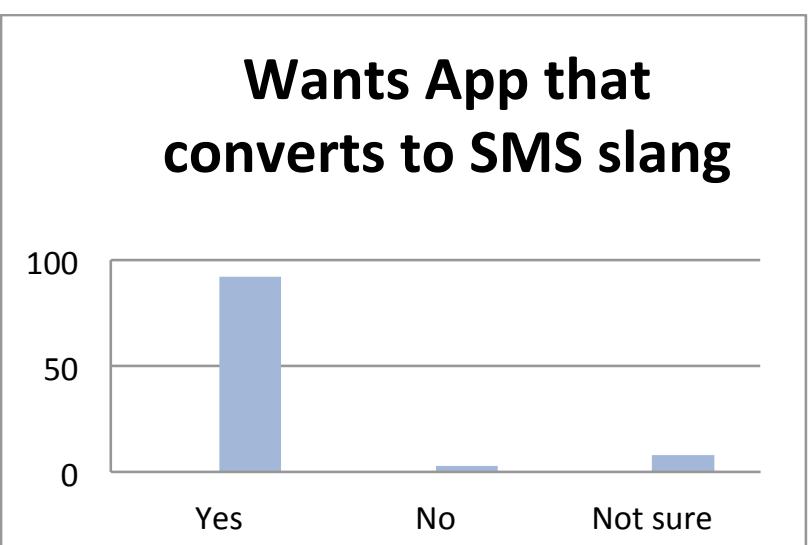

Figure 5. Those who want an app that converts to SMS slang

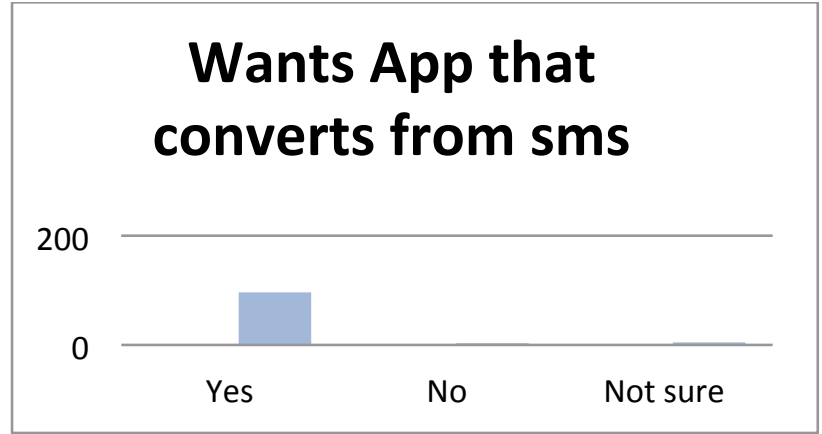

Figure 6. Those who want an app that converts from sms slang

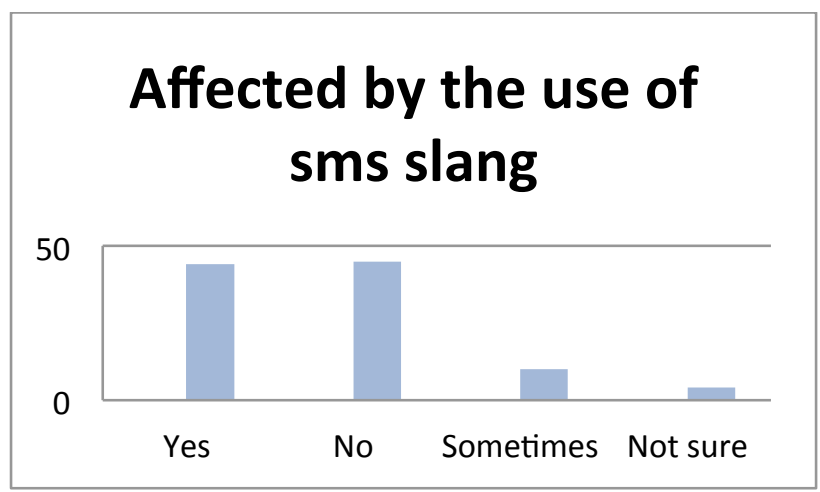

Figure 7. Affected by the use of SMS slang in formal writing

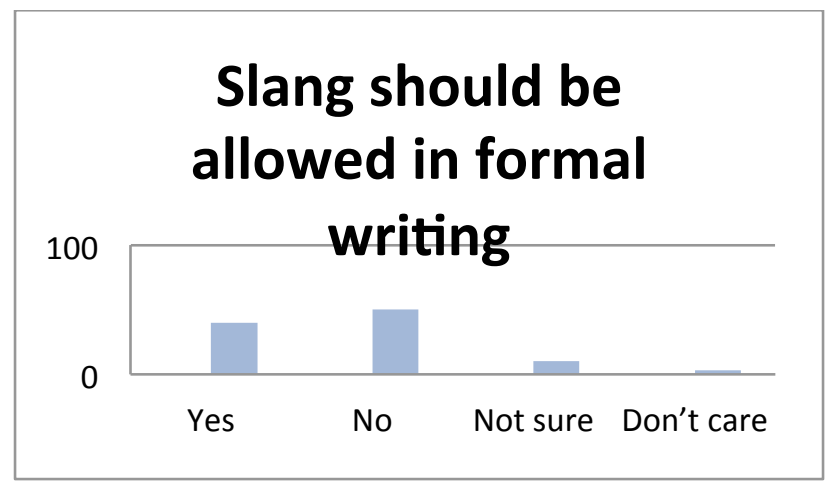

Figure 8. Allow the use of slang in educational institutions. 


\section{ANALYSIS}

\section{A. Analysis of user responses}

The following are findings from the responses provided by respondents from the needs assessment questionnaire. The age range 16-25 years accounts for 70 (67.96\%), this is where the bulk of UG students fall into, 26-35 years accounts for $23(22.33 \%)$, and above 35 years accounts for $10(9.7 \%)$ and this is where the staff fall into. Those that use SMS and chat slangs are $88(85.54 \%)$ and $81(78.64 \%)$, respectively. On the motivation for use of slang in SMS, $73(70.87 \%)$ use slang to save cost and time, while $11(10.68 \%)$ use it to save time and only $6(5.82 \%)$ use it to save cost only. On the need for an application that converts SMS slang, 92(89.32\%) would like to have an app that converts regular SMS text to slang, while 96(93.2\%) would like to have an app that converts a SMS written in slang to proper English language. Among the UG students those who said that SMS slang affect them in formal writing are 44(42.72\%), while those who said they are not affected including the PG students and staff are $45(43.69 \%)$. And as for making slang acceptable in educational institutions, $40(38.83 \%)$ all who are UG students are in support, while $50(48.54 \%)$ are opposed to the idea, while $10(9.7 \%)$ are undecided.

The user responses clearly showed the need to develop an application that converts SMS slangs of which over $90 \%$ are in favour. This motivated us to proceed with the work. In section 3.2 we reviewed similar applications, their strengths and weaknesses. And in section 3.3, we showed the analysis and design of the proposed system.

\section{B. Analysis of Existing Systems}

Some similar applications were also reviewed in the course of this work. They include Transl8it (translate it) located at transl8it.com, a web based application that has an input box to type texts to be translated. There are two options: lingo to English and English to lingo. This app allows the user to type either, a lingo slang and click the 'translate it' button to English, and vice versa. The limitation of this application is that it cannot be ported to a mobile device, and besides the dictionary content is limited to a few common sms slangs, about seventy-five. It however, has a forum that allows registered users to add lingo. Another similar application is called SMS Everywhere, found at www.smseverywhere.com. This is also web based, offering input boxes to key in words and phrases to be translated at the click of the submit button. Unlike transl8it, this app does not offer the option for users to add new words to the dictionary. On the other hand, it has more dictionary content than the former. Lingo 2 Word is another app found at www.lingo2word.com. This offers similar interface and functionalities with Transl8it, but does not have option to add new words. A number of other applications were found on the Google Play Store. They include, Internet Slang Dictionary, SMS Slang Translation, Chat Slang Dic, etc. Both SMS Slang Translation and Chat Slang contain several thousand slang's list. The former allows users search for specific slang, as well as send their own slang to the developers. Both apps have hit over 1000 downloads and have user ratings of $4.0 / 5.0$ and $3.9 / 5$, respectively.

\section{Analysis and Design of the Shortword App}

The statements of requirements for the application are listed below. The application is expected to:

1. Translate from shortcuts/shortwords/shortcodes/ abbreviations to fullwords/fulltexts and vice versa.

2. Import Contacts from phonebook for sending SMS.

3. Send SMS.

4. Import Message from inbox for conversion.

5. Export/Save as draft unfinished conversion.

6. Suggest words and shortwords as you type.

7. Install and update conversion dictionary from online.

8. Use Remote offline dictionary in the absence of Internet access.

9. Update your phone dictionary for personal shortword not captured by the app.

10. Contribute to the development of the app by uploading your shortwords suggestions online.

11. Restore your factory settings to default.

12. Control your user's preference in the settings.

\section{Design Architecture}

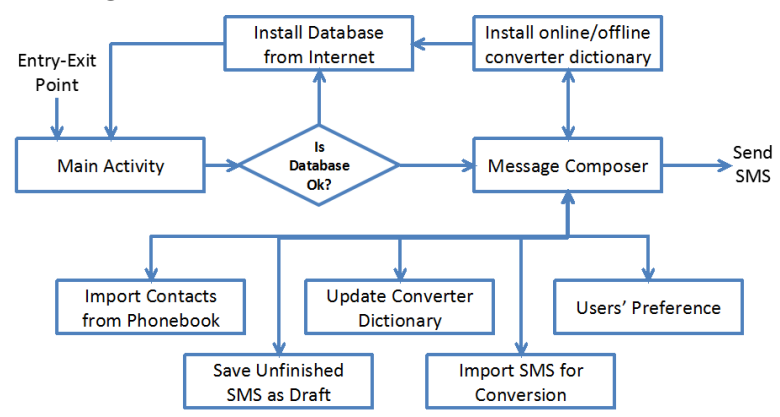

Figure 9. Design architecture of the application

\section{E. Design Methodology}

The methodology used is Object Oriented Analysis and Design Methodology.

\section{F. Design Explanation}

The shortword app has the principal task of shortening text messages while retaining their original meaning, as well as allowing a user convert shortword/slang into more comprehensible full word/sentences.

\section{G. How It Works}

On Start: The Home Screen is the target of the launched app. The app starts from the mainActivty which is limited from doing any other work apart from verification processes. The Main Activity checks the status of the database; whether the database exists for the first time (which is supposed to return false on first use and true on other uses). On the occasion of the absence of the database, the app through the main activity takes the user to a synchronization process, installs the database and associating tables at the same time. In the synchronization process also, the app checks for the contents of the database tables, some will return empty after the first installation and afterwards the reverse is the case. The table contents can be empty again if a user at any point in time restores the app's factory settings, which will even drop all the custom settings too. In the case of empty table the synchronization process continues populating the database tables from the 
database table online at which point, internet access is needed. The app also in the absence of online internet access provides the alternative option of populating the tables from an immediate offline data built into the app as series of array. This second option is highly limited as the database dictionary for the proper translation is insufficient of data. The app also has the option of allowing the user update the content of the dictionary on his device at any convenient time provided internet access is guaranteed. The phone immediate app dictionary can also be directly updated by the user by providing the short word and its full interpretation; this update is beneficial only to the user, but can be made generally and universally beneficial by uploading the new short words suggestion to the app online dictionary which can be downloaded by any other user.

\section{H. Operations}

In the usage, the user is expected to type the message either in full text or short word. The app can switch between the two modes and is indicated on the home screen. When the app is the full text mode, a user types his message in normal full words and as he/she types, the auto complete option of the input fields suggests the related words for auto completion. At the end of message composure, a user can press shortword button to convert the typed message to short word. In the translation process; the app goes through 3 levels of conversion, viz-a-viz: Level 1, 2 and 3. The level shows the extents of shortening a word, phrase, clause or sentence, for instance: the clause 'Thank God it is Friday' can be shortened at level 1 as 'Tnk God its Fri' and 'Tgif' at level 2. Also, the phrase 'Good morning' can be shortened to 'Gud mornin' at level 1 , 'Gud morn' or "g'morn" at level 2 and "g'am" at level 3.

As much as you convert from fulltext to shortword, backward conversion is also applicable by clicking fullword button and also the same 3 levels of conversion is achievable too.

\section{Accessories}

The app uses for features to enhance its usage:

- Import: The import option helps user to pick a text message from already composed, sent or received text message from inbox and perform the conversion on it.

- Export: this option helps the user to save unfinished text message as draft in the phone draft box and continue with it later.

- Choose From Phonebook: This enable user to pick a receiver's phone number from the normal phonebook of the phone. The enhance contact specification.

- Send: This option enable a user to send a shortened text message to the intended receiver at the normal network SMS charge. This particular option uses the Android send SMS API interface to connect and route the sending text message via a SIM network to the intended receiver. The API is a line of code that uses the syntax and program to handover a text message to the SMS Manager for further forwarding.

- Users Define: The app allows users to define the look of their graphical interface; change their background colour, font size, weight, style, and colour and as well button orientation. It also allows user to enable or disable some features like database auto synchronization, auto complete and word suggestion features.

\section{IMPLEMENTATION}

The implementation platform was on Eclipse Android 4.2.2 API Level 17

\section{A. Procedures}

The application was developed on the Eclipse ADT, and compiled on SDK Bundle Windows-X86 with Android Virtual Device Manager. The initial debugging, testing and running was on the android emulator while the final deployment on was done on Android real devices (Samsung Galaxy S5 and Techno P5)

\section{B. Android Apis Used}

Send Message API - Use the code to connect to message sending API

\section{Components Of The App}

Almost all the tools of Android Development were employed in developing the app. The Development Environment used is Android Eclipse 4.2.2 which was interfaced with the compiler kenown as Android Virtual Machine (AVM). The SDK offers the add-ons, build-tools, platform-tools, docs, references, and system-images. All the above mentioned are contained in the Android Developers Tools (ADT).

- JAVA: The functions in the Android app were programmed with Java programming language which was organized in classes and methods and compiled using the virtual compiler, AVM. The Java code of the android comes in the form of Activity, ListActivity, Services, etc.

- XML: The layouts of the app were written with XML codes and non-reusable data stored as XML files. The XML holds static information mainly for labeling of the layouts and their components.

- SQLITE: This served as the database of the app and holds dynamic data that can be inserted, deleted, update and queried.

\section{How They Were Applied In Shortword App}

The app has 7 major classes and 6 sub classes. The major classes include: MainActivity.class, MsgComposer.class, OnlineDbSync.class, PhoneInterface.class, DbConnect.class, ImportlistView.class and Settings.class. They are supported by the following subclasses: InsertMySqlDb.class, supports DbConnect.class and OnlineDbSync.class when MySql data is being extracted to Sqlite database. SMSRead.class, supports the PhoneInterface.java and importListView.class when SMS from the phone is being used by the app. ServiceHandler.java, helps the OnlineDbSync.java to connect to the internet and access JSON Object information. ImportArrayAdapter.class is used by all the classes that extend ListActivity in arranging and adapting arrays of data in a list appearance. SpaceTokenizer.class is a subclass that helps in adding a space when one of the suggested words/sentences/phrases/clauses is selected. SMSData.class arranges the SMS in a manner that the SMS Manager can act on it for easy retrieval of a particular associated Originating Address, Date, Body, Status and 
ID of a text message. Action.class is used by all the classes discussed above in performing some basic actions and animations in the app.

The app user interface is done with XML which is presented in the form of layout, values and menu. Together with the drawables, they are collectively called resource files. The Layout XML is used for building the interface of the view containers and their components. The app has the following layout files; activity_main.xml, activity_composer.xml, settings_ui.xml, settings_db.xml, settings_ac.xml, activity insertmysql.xml, activity_help.xml, activity_about.xml, activity_add_to_dictionary.xml, activity_settings.xml, list_mobile.xml and activity_spinner.xml. The value XML holds static data for the app. They include: strings.xml, dimens.xml and styles.xml. The Menu XML holds various menus for the app. They include: settings.xml, main.xml and custom.xml. The drawable folder holds various densities of images for the app.

\section{E. Screenshots}

Presented below is the implementation tool for the development of the app.

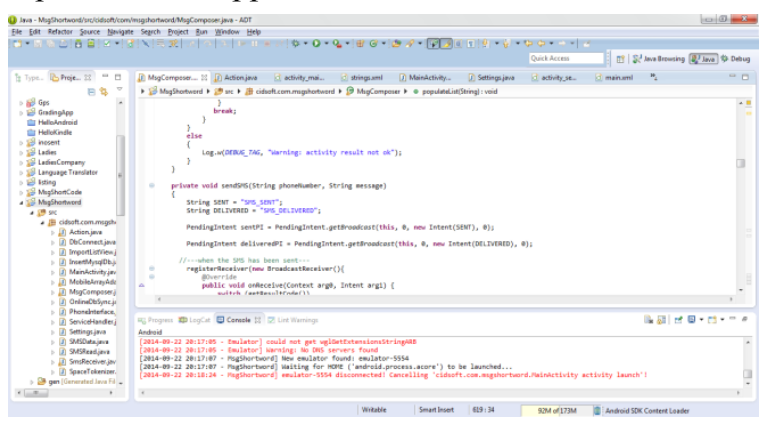

Figure 10. Eclipse SDK

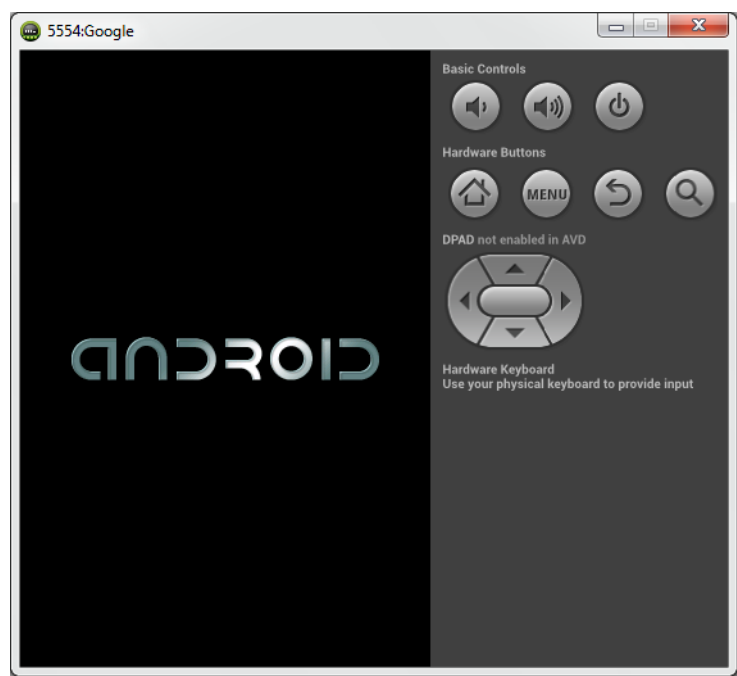

Figure 11. Android Emulator

App Screenshots: Presented below is the screenshot of the app:

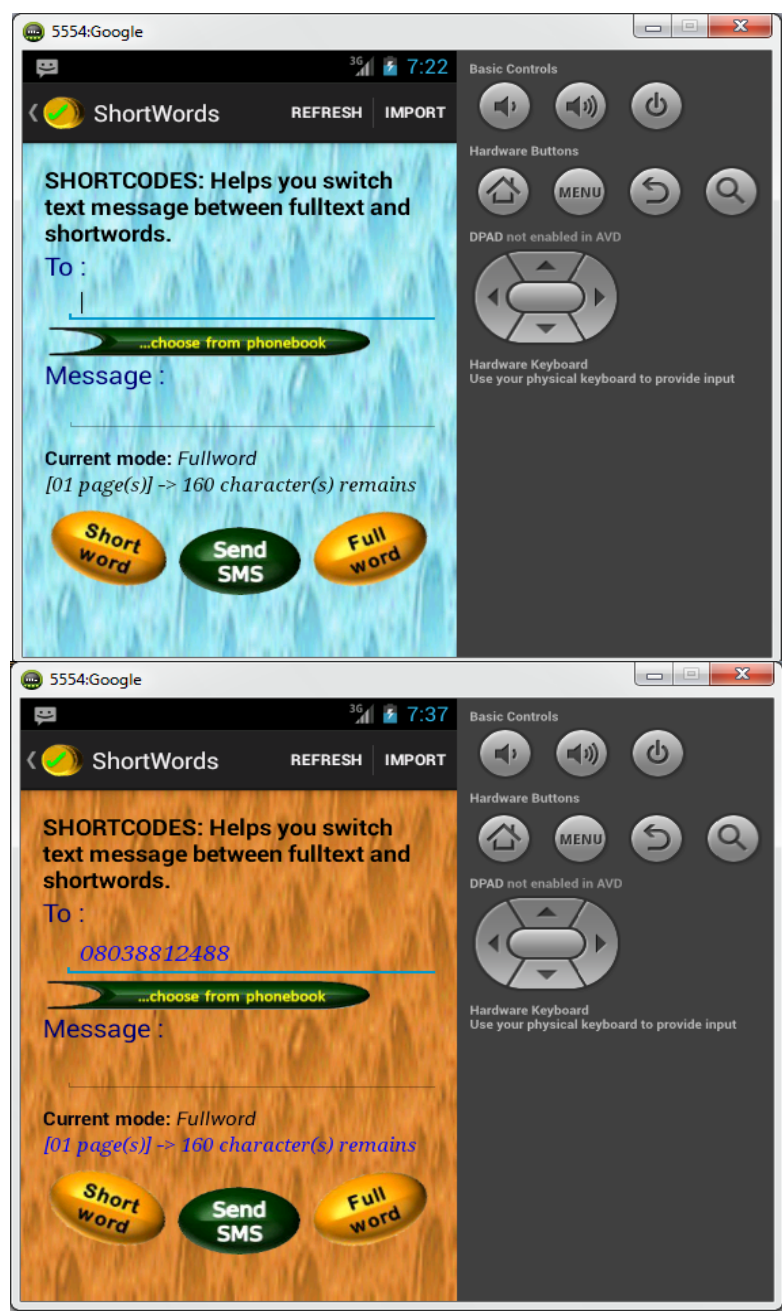

Figure 12. Shortword App with different background colour.

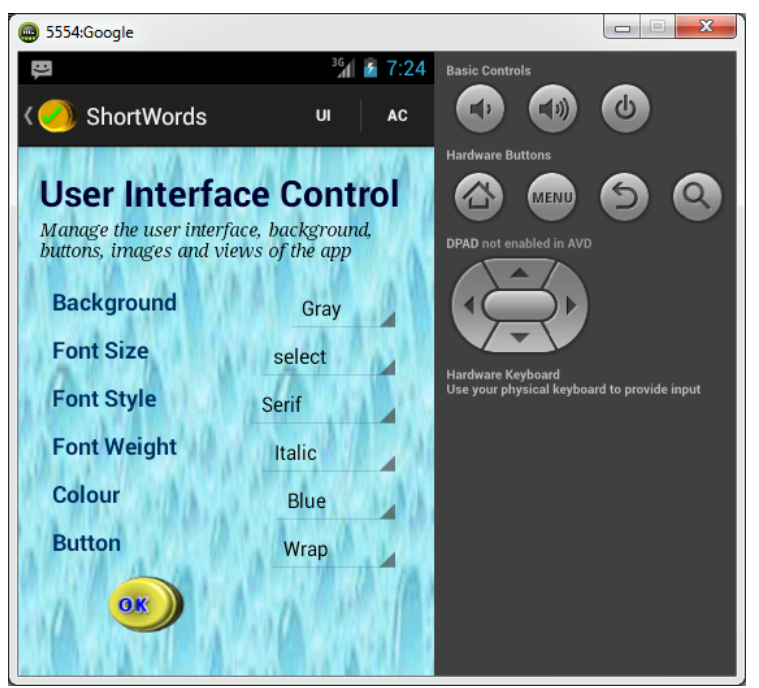

Figure 13. Users' define Settings Panel 


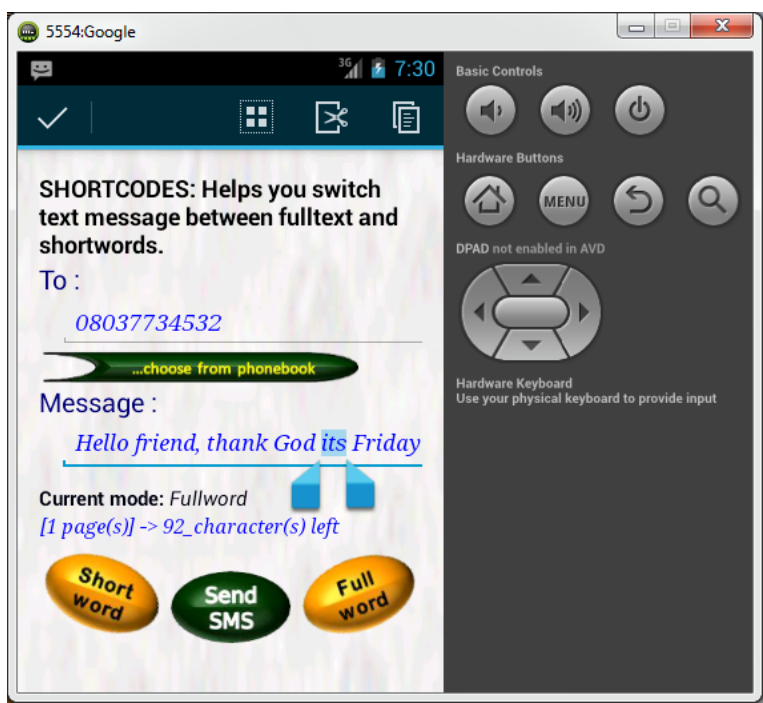

Figure 14. Message converted to Fulltext

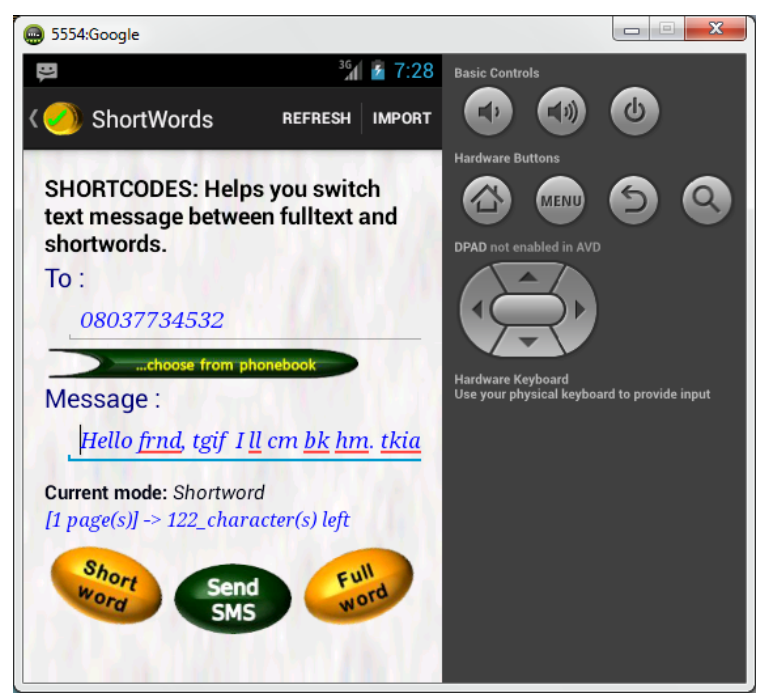

Figure 15. Message converted to Shortword

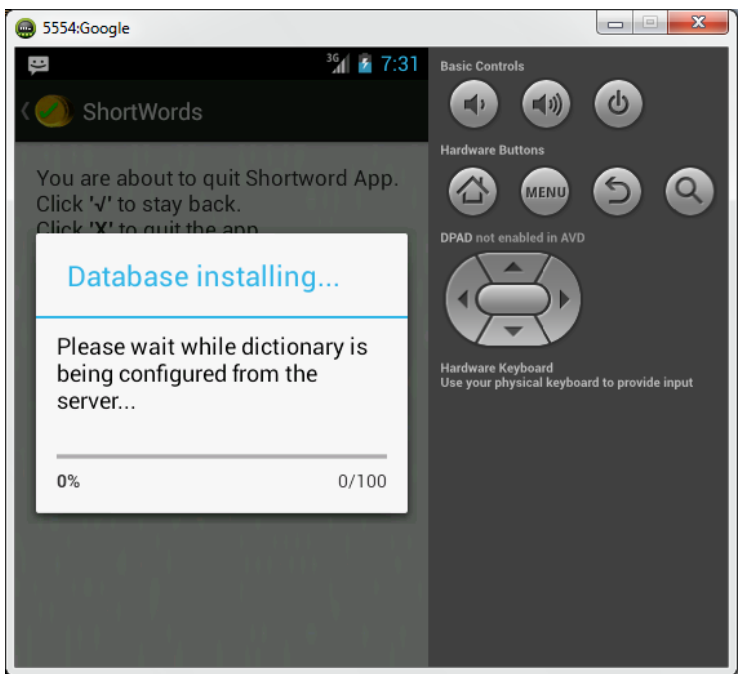

Figure 16. Installing Database from Internet

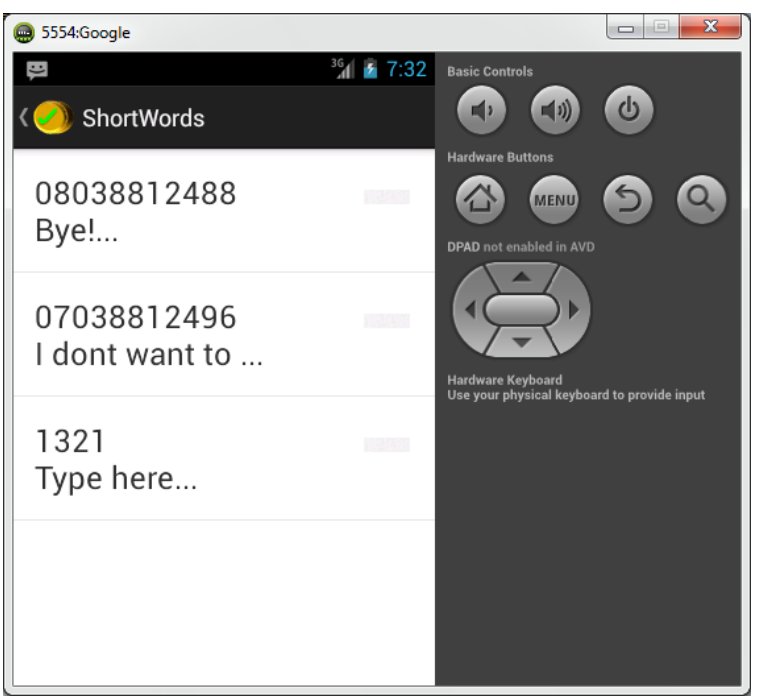

Figure 17. Import Message from SIM/Inbox

\section{User Evaluation Of THE APPLICATION}

The application was hosted on the web where users downloaded it from and installed in their Android devices. The application was installed on different Android phone makes such as Samsung, Nokia, Techno, etc. and there were no compatibility issues, as long as the device had Android version of 3.0 and above. On first installation, the database has to be synchronized from the web. Updates also require synchronization of database. Users were encouraged to use the app and fill an online user evaluation form. The form contained the following rating fields:

- Sex of Respondent

- Device Type/Make

- Installation Rating (with options: Fast and Smooth, Slow but Smooth, and Slow and not Smooth)

- Usability Rating (with options: Easy to Use, Moderate, Not Easy to Use)

- Translation Rating (based on a scale of $1-5$, in ascending order)

- Word Shortening Strength (based on a scale of 1-5, in ascending order)

- Efficiency Rating (with options: High, Moderate and Low)

- Necessity/Relevance Rating (with options: High, Moderate and Low) 5.1 .

The results of the user evaluation are shown in section

\section{A. Results and Discussions}

The result of the user evaluation is discussed in this section.

- Installation Rating: Users are expected to rate how fast and smooth the installation process from the online repository. Actually, the speed of installation is dependent on the network connectivity of the user's device and not on the application itself. Figure 18 shows the installation rating chart, where $70 \%$ of the users rated the installation rate as being fast and smooth, 20\% rated it as slow but smooth and $10 \%$ rated it as slow and not smooth. 


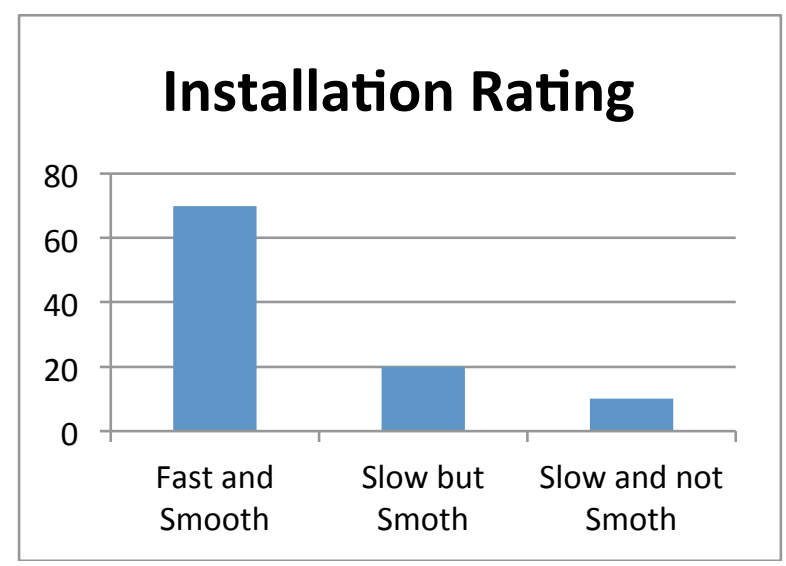

Figure 18. Installation Rating

- Usability Rating: Usability rating measures who easy it is for a first time user to navigate through the app and achieve the required tasks. This is measures how intuitive the use of the app could be, including userfriendliness, application responsiveness, etc. The figure 19 shows the result of the user's usability rating, where $80 \%$ of users rated the app is being easy to use and the remaining $20 \%$ rated it as moderate.

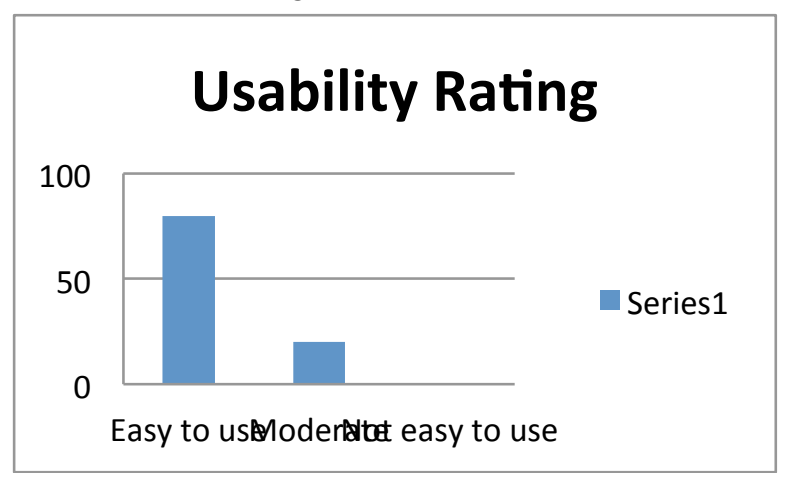

Figure 19. Usability rating

- Translation Rating: Translation rating measures how well the app translates words from short word to full word and vice versa on a scale of 1-5. Figure 20 shows the chart of the users' evaluation on translation rating. $10 \%$ of users rated the translation rate as 5 , which is the highest rating, while $50 \%$ rated it as 4 , $20 \%$ of users rated it 2 and 3 , respectively.

\section{Translation Rating}

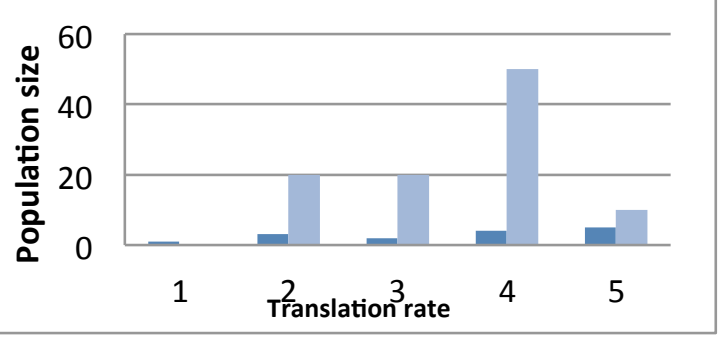

Figure 20. Translation Rating

- Shortening Efficiency: Shortening efficiency measures the reduction in the length of the SMS message after a conversion is made from full word text to short word abbreviations/slangs. Figure 21 shows a chart of users' evaluation of this criteria, where $20 \%$ of users gave it a rating of 5 on a scale of $5,50 \%$ of users gave it a rating of $4,20 \%$ rated it as 3 and $10 \%$ rated it as 2 .

\section{Shortening Efficiency}

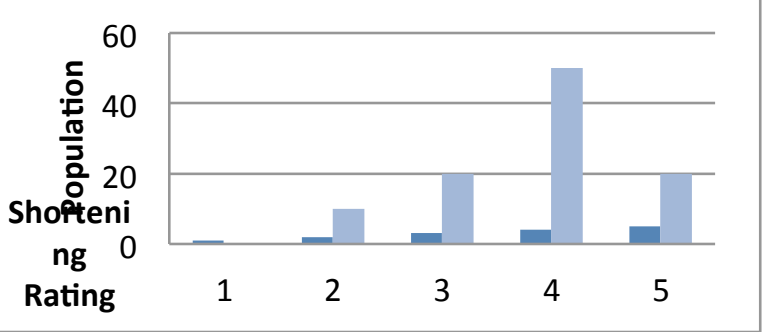

Figure 21. Word shortening efficiency

Huffman coding scheme $[17,18,20]$ has be found useful in reducing message size. The shortening efficiency can also be calculated using the Huffman's compression formula in equation 1 according to [18],

$$
\text { Compression }=\text { Compressed }
$$

SMS

size/Original SMS size * $100 \ldots \ldots . . . \ldots . .(1)$

This application adopted 'human interpretive compression' [17] which uses abbreviations, phonetic respelling, initialization, slangs, etc. to reduce the size of the SMS. The above equation can be re-written as shown in the equation 2 ,

$$
\text { Shortening Efficiency }=M_{a c} / M_{b c} * 100
$$

Where $\mathrm{M}_{\mathrm{bc}}$ is message length before conversion andM $\mathrm{M}_{\mathrm{ac}}$ is the message length after conversion.

A typical scenario experienced during the use of the app is shown in figures 14 and 15 , where the $m_{b c}$ is 68 characters (i.e.160-92) and $\mathrm{m}_{\mathrm{ac}}$ is 38 characters (i.e.160122). A typical SMS has 160 characters and a memory size of 1120 bits (i.e. $160 * 7$ bit). Then the shortening efficiency can be calculated using equation 2 to arrive at $55.88 \%$. But according to [18] using the Huffman's compression algorithm in which more frequently occurring symbols are coded using shorter code words to generate a frequency table, can yield an efficiency of up to $89.44 \%$. Huffman's compression algorithm offers better compression than arithmetic coding which additional memory will need space to save arithmetic coding probability table. [18][19].

The authors in [17] applied the Huffman compression for a Nokia based SMS compression app, and had a typical result like $\mathrm{m}_{\mathrm{bc}}$ of 271 and $\mathrm{m}_{\mathrm{ac}}$ of 139 characters, respectively, which gave efficiency of $48.71 \%$ using equation 3 . They achieved this by doing a second level conversion to 8-bit ASCII character with value from 128 to 255.

Compression $=($ Total char in original SMS - Total char in compressed SMS)

\section{in original SMS}

Total char

- Efficiency Rating: Efficiency rating measures nonfunctional requirements like how the app uses resources like memory, fits into display sizes, manages colours and how quickly it responds to instructions. 
Figure 22: Efficiency rating chart shows users responses, in which $80 \%$ rated it high, while $20 \%$ and $10 \%$ rated it moderate and low, respectively.

\section{Efficiency Rating}

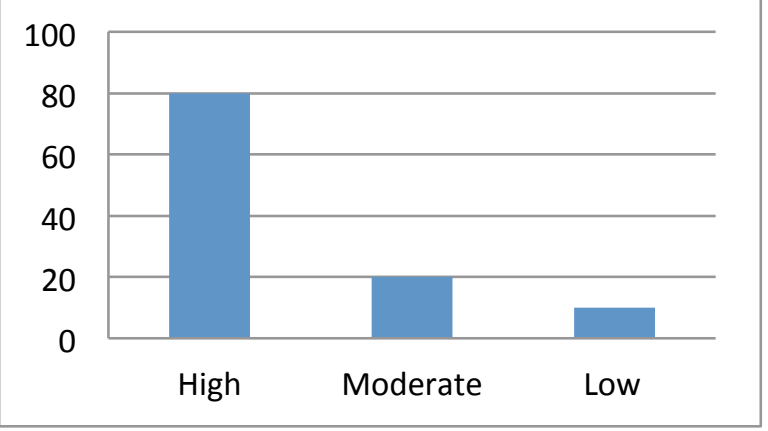

Figure 22. Efficiency rating chart

- Relevance of the application: Figure 23 shows that $90 \%$ of the users who evaluated the application thinks that is a relevant application. This further agrees with the needs assessment report in which over $90 \%$ of the respondents indicated their desire to have an app that converts to/from SMS slang as shown in figures 5 and 6.

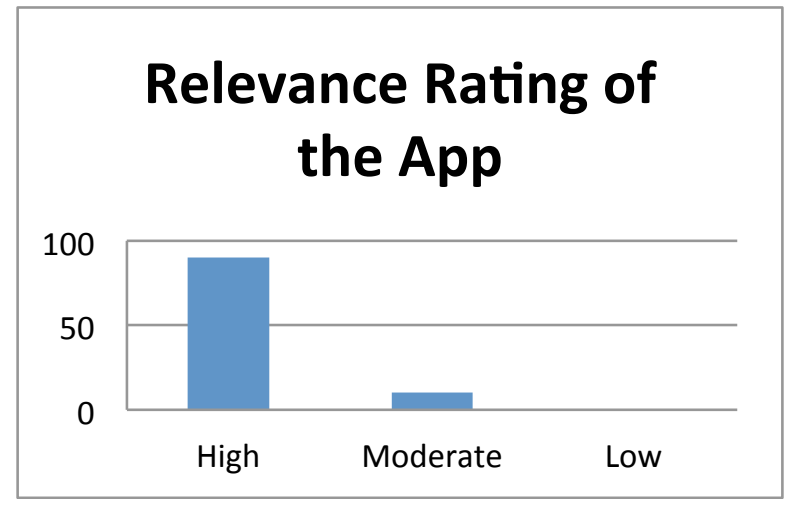

Figure 23. Relevance chart

\section{CONCLUSION AND FUtURE WORK}

This work has been able to determine that users of mobile phone desire an application that aids in SMS coding and deciphering, an application that will ultimately reduce the cost and time of composing and sending a SMS message. Having carefully observed software engineering standards, we have developed an application for all Android devices that is usable, efficient, free, and compresses messages to at least $50 \%$, depending on the contents of the message. Future work will focus on increasing the dictionary contents and employing compression algorithm like the Huffman coding or any other better one to achieve a compression rate of at least, $80 \%$.

\section{REFERENCES}

[1] www.grabstats.com/sttmain.aspx

[2] GSM Doc 28/85 "Services and Facilities to be provided in the GSM System" rev2, June 1985

[3] Why text messages are limited to 160 characters. www.latimesblogs.latimes.com/technology/2009/US/inventedtext-messaging.html
[4] Textual Relations: Couples who text too much aren't as in love as they want you to think www.healthland.time.com/2013/10/31/ifyour-guy-is-texting-you-a-lot-hes-not -that-into-you/

[5] Shazia Aziz, Maria Shamim, Muhammad Faisal Aziza and Priya Avais, Elixir Ling. \& Trans. 55 12884-12890, 2013.

[6] Salameh S. Mahmoud, "The effect of using english sms on kau foundation year students' speaking and writing performance," American International Journal of Social Science, Vol. 2, No. 2;

[7] Ochonogor W. C. , Alakpodia N. O. , Achugbue I. E., "The impact of text message slang (TMS) or chartroom slang on students academic performance," International Journal of Internet of Things," Vol. 1(2): 1-4 doi: 10.5923/j.ijit.20120102.01, 2012

[8] TAMUCC Wiki - Sgarza, The Impact of Short Message Service (SMS) Language on Basic Writing, Available at: http://www.tamucc.edu/wiki/SGarza/TheImpactOfSMSOnBasicW riting

[9] Sabreena Ahmed, Abu Sadat Nuruallah, and Subarna Sarkar, "The use of sms and language transformation in Bangladesh," Spectrum: Journal of the Department of English, University of Dhaka. Vol. 6 and 7, pp.107-139,

[10] Spekali, "About some important aspects of using abbreviations and SMS language in the modern English," Electronic Bilingual Scholarly Peer-Reviewed Journal "Spekali" of the Faculty of Humanities at Ivane Javakhishvili Tbilisi State University, Available at: http://www.spekali.tsu.ge/index.php/en/article/viewArticle/5/51

[11] Annie Martin, "Texting slang creeps into student writing". Available at http://www.newsjournalonline.com/article/20130817/NEWS/130819461

[12] David Crystal, Will Self And Lynn Truss On The Joy And Horrors Of Texting. Available at: http://www.theguardian.com/books/ 2008/jul/05/saturdayreviewsfeatres.guardianreview, 2008

[13] Solomon Ali Dansieh, "SMS texting and its potential impacts on students' written communication skills," International Journal of English Linguistics Vol. 1, No. 2, 2011 http://dx.doi.org/10.5539/ ijel.v1n2p222

[14] Salomé Geertsema, Charene Hyman and Chantellevan Deventer, "Short message service (SMS) language and written language skills: educators' perspectives," South African Journal of Education Copyright(C2011 EASA Vol 3 1:475-487, 2011

[15] Clare Wood, Nenagh Kemp and Sam Waldron, "Exploring the longitudinal relationships between the use of grammar in text messaging and performance on grammatical tasks," British Journal of Developmental Psychology, 32, pp.415-429, 2014 http://dx.doi.org/10.1111/bjdp.12049

[16] Alias Mohd and Wong Thai Min, "Short message system (sms) compression on mobile phone-sms zipper," Universiti Teknologi Malaysia: Journal Teknologi, 49(D) Dis 2008: 173-187, 2008.

[17] Kirti Madhurkar Battase, Neha Vijay Barve, Parinita Bajirao, and Lata Vitthal Sanap, "Android application for SMS compression," International Journal of Research in Advent Technology, Vol. 2, No.4, 125-128, 2014

[18] Kumbhar P.Y, "SMS Compression using arithmetic coding modification," IEEE International Conference Proceedings on Devices, Circuits and Systems (ICDCS), pp. 585-589, 2012 http://dx.doi.org/10.1109/icdesyst.2012.6188776

[19] Huffman coding, Wikipedia Online encyclopedia. Available at: http://www.wikipedia.org/wiki/Huffman_coding. Retrieved on 10th February, 2015.

\section{AUTHORS}

C.N. Udanor is with the Department of Computer Science, University of Nigeria, Nsukka, 410001 Nigeria (email: collins.udanor@unn.edu.ng).He is

C.I. Nwoye is with the Department of Computer Science, University of Nigeria, Nsukka, 410001 Nigeria. He is now a graduate student of the University of Winnipeg, Manitoba, Canada R3B 2E9 (e-mail: chinedu.nwoye@unn.edu.ng).

Submitted, 24 June 2015. Published as resubmitted by the authors on 03 September 2015. 